\title{
PERUANOS EN EL CRUCE DE FRONTERA HACIA ARGENTINA. REFLEXIONES SOBRE LAS POLITICAS DE CONTROL MIGRATORIO DESDE LAS SUBJETIVIDADES DE LOS MIGRANTES
}

Peruvians in the border crossing to Argentina. Thoughts about
Migration control policies from the experiences of the subjects

Angélica Alvites Baiadera*

\begin{abstract}
Resumen. El objetivo de este artículo es analizar las políticas de control migratorio desde las subjetividades de los migrantes, al tomar como punto de análisis el cruce de frontera. Específicamente, se pregunta cómo los migrantes peruanos atraviesan, disputan y negocian su ingreso a territorio argentino, en los cruces de fronteras. El desarrollo de este artículo se sustenta en una metodología cualitativa, basada fundamentalmente en entrevistas en profundidad con peruanos y peruanas que migraron desde los años 50 en adelante. Se construye una periodización de esta migración hacia Argentina y se establece un conjunto de hitos sobre cómo los peruanos experimentan las políticas de control. Los entrevistados se perciben como sobrevivientes de estos controles, al entenderlos como condición sine qua non para el cruce hacia Argentina.
\end{abstract}

Palabras claves: políticas de control migratorio; subjetividades; cruce de frontera; migración peruana; Argentina.

Abstract. The objective of this article is to analyze the Migration Control
Policies from the subjectivities of migrants, by taking the border crossing
as the starting point of the analysis. Specifically, how Peruvian migrants
cross, dispute and negotiate their entry to the Argentine territory is asked.
This article is based on a qualitative methodology, fundamentally with in-
depth surveys to Peruvian women and men who migrated from the Fifties
onwards. A periodization of such migration to Argentina is built, and a set of
milestones on how Peruvians experience the control policies is established.
The interviewees perceive themselves as survivors of such controls, by
understanding them as a sine qua non condition for the crossing toward
Argentina.

Keywords: migration control policies; subjectivities; border crossing; Peruvian migration; Argentina.

Becaria posdoctoral del Consejo Nacional de Investigaciones Científicas y Técnicas (CONICET), en la Universidad Nacional de Villa María, Córdoba, Argentina. Córdoba, Argentina. 


\section{Introducción}

Este artículo aporta a la discusión sobre las políticas de control migratorio desde la mirada de los sujetos que cruzan las fronteras. Así, nos preguntamos, desde el campo de los estudios migratorios, cómo los migrantes peruanos atraviesan, disputan y negocian las políticas de control migratorio, tomando como punto de análisis el cruce de frontera ${ }^{1}$. Si bien comprendemos que las fronteras exceden la idea de límite territorial, separación constitutiva de lo político, al menos en el marco del Estado-nación, en este artículo analizamos el cruce de frontera como el momento constituyente que clasifica a nacionales de no-nacionales, donde las migraciones son co-constituyentes del espacio fronterizo, el cual se encuentra en constantes tensión, conflicto y contestación².

En contraste con las concepciones de la migración como una variable dependiente de factores objetivos o de los migrantes como actores de elección racional, la propuesta presentada examina la dimensión subjetiva de la migración como una de las razones de la persistencia de los momentos de autonomía de la migración dentro de los regímenes de fronteras y control de las migraciones (Mezzadra, 2015; Idem, 2014). Entendemos que las migraciones y las fronteras, desde la experiencia de los sujetos, son figuras claves para comprender las políticas en nuestro presente contemporáneo global (De Genova, Mezzadra, Pickles, 2014).

El desarrollo de este artículo se sustenta en una metodología cualitativa, a partir del análisis de entrevistas en profundidad a migrantes peruanos que llegaron a Argentina desde los años '50 hasta 2015'3, articuladas tanto con fuentes secundarias como con observaciones y notas de campo, tanto en Perú como en Argentina ${ }^{4}$. Las entrevistas se realizaron entre los años 2014-2015 en el marco del trabajo de campo de mi tesis doctoral (ya defendida) ${ }^{5}$. La

1 En otros artículos se trabajaran otros tipos de fronteras, pues éstas ya no son únicamente los confines de los Estados, sino que están en el centro del campo político (Mezzadra, 2015). Véase, Alvites Baiadera, em prensa.

2 Según Kalm (Governing Global Migration) las investigaciones sobre el control en frontera ha sido descuidado por la mayoría de las escuelas que estudian los procesos migratorios. Los estudios sobre fronteras tomaron impulso, a finales del siglo XX, especialmente desde los eventos del 11 de septiembre de 2001 en EEUU, con el auge de los trabajos sobre migraciones transnacionales y control, gestión y administración de éstos por medio de políticas que apostaban a la construcción de muros, guardias fronterizas, equipos sofisticados de detección electrónica, controles biométricos, centros de retención, entre otras medidas En América del Sur los estudios de frontera en general son escasos (Liberona Concha, 2015; Tapia Ladino, 2017; Grimson, 2004; Sassone, Cortes, 2010).

3 Quince entrevistas en profundidad, las cuales son citadas de la siguiente manera: "Nombre ficticio, año de llegada por primera vez a Argentina".

4 Se realizaron dos estancias de investigación en Perú en 2014 y 2015. La primera subvencionada por una beca de la Red Macrouniversidades. Las fuentes secundarias utilizadas fueron principalmente los acuerdos bilaterales entre los Estados, acuerdos regionales y normativas de cada territorio.

5 Tesis doctoral: Políticas migratorias y subjetividades migrantes: peruanos en Argentina, dirigida por el Dr. Eduardo Domenech. Defendida en marzo de 2017. 
muestra se diversificó no solo por períodos de llegada a la Argentina (desde los años '50 hasta la actualidad), sino también por las experiencias y relatos de vida. Su selección se realizó a través de un diseño secuencial y de principio de selección gradual (Sautu et alii, 2005). Este tipo de entrevista permitió adentrarse en la vida cotidiana de los migrantes peruanos, poder detallar, descifrar y comprender las preocupaciones, temores y prácticas que los sujetos recuerdan sobre las políticas de control migratorio en frontera. Esta tarea no fue sencilla, ya que se requirió de dos o más encuentros con cada entrevistado, ganar en confianza, para poder construir minuciosamente su experiencia. El periodo analizado responde, por un lado, a los cambios desde mediados del siglo XX en la composición de los grupos migratorios desde la interrupción de los ingresos de ultramar y al giro restrictivo de la normativa migratoria en Argentina (Pacecca, Courtis, 2008). Por el otro, el corte hasta el año 2015 se debe a que el registro se hizo hasta ese periodo, siendo el último año de gestión del gobierno de Cristina Fernández (a partir de la asunción de la Alianza "Cambiemos" a la presidencia, desde 2016, se produjeron cambios significativos sobre las políticas de migración, al adquirir cierta visibilidad y vitalidad las categorías como control de ingreso y permanencia (Alvites Baiadera, 2017b), las cuales requerirán un análisis pormenorizado que escapan a los datos obtenidos en esta investigación).

Para alcanzar el objetivo propuesto, el artículo se estructura de la siguiente manera: primero se presenta una periodización de la migración peruana en Argentina, segundo, se establece un conjunto de hitos sobre cómo los peruanos experimentan las políticas de control. Los cuales los definimos como: sortear la sospecha por subversión, por falso turista, por ser portadores de enfermedades y por presentar documentación espuria.

\section{De trayectorias sociales y periodización de la migración peruana hacia Argentina}

Las trayectorias de los entrevistados son heterogéneas ${ }^{6}$, la mayoría proviene de ciudades urbanas, aunque en sus historias familiares la migración interna, por lo general, de pequeños asentamientos a grandes ciudades los atraviesa. Esta migración interna antecede a la migración internacional. Desde principios del siglo XX, se observan jóvenes peruanos de clase alta estudiando en la Universidad pública de Argentina, principalmente en La Plata, Buenos Aires y Córdoba (Vera De Flachs, 2006), presencia que se mantuvo estable hasta fines de los años '40 (León Prado, 2010). Desde mediados de los años '50 se registra un aumento en la población de peruanos y en las últimas tres décadas es uno de los grupos poblacionales que más ha crecido en Argentina (Texidó et

\footnotetext{
6 Por cuestiones de espacio no se profundizará sobre la trayectoria individual de cada entrevistado.
} 
alii, 2008). Las posibilidades de acceso irrestricto y gratuidad de la Universidad pública y las redes sociales incipientes permitieron analizar la migración hacia Argentina como una opción para estudiar, residir provisionalmente y volver a Perú en mejores condiciones socioeducativas ${ }^{7}$. Así lo relata un entrevistado que llegó a mediados de los años ‘50:

Vinimos varios en la década del '50, muchos vinieron a estudiar. Sí, vino más gente a estudiar, éramos estudiantes. Acá había facilidades de ingreso... cuando ingresamos en dos días arreglabas tus papeles PUM, PUM [hace un golpe con la mano] y ya estábamos adentro. (José, 1957)

La migración peruana se mantuvo estable hasta fines de los años '80, aunque desde los años '60 cambia el perfil sociodemográfico y ya no serán solo los jóvenes varones de clase alta los que migran, sino también los de clase media con expectativas de acceder a estudios de nivel superior (Falcón Aybar, Bologna, 2013). En Perú, entre 1950 a 1980, se produce un "boom universitario", donde se crean nuevas universidades (Contreras, Cueto, 2013, p. 367), sin embargo su ingreso fue restringido para la mayoría de la población. Lautaro, uno de los entrevistados, expresa lo vivenciado:

Mi viejo me dijo "tenés que estudiar, ¿qué vas a estudiar en Perú?". Y viste que en Perú es más difícil que la mierda ingresar. Y yo pensé: "estudiar para no ingresar", porque si no ingresas allá te quedas de vago, por lo menos en Argentina algo saldría... Así que le comenté a mi papá, que un amigo estaba estudiando en La Plata. Mi papá conocía la familia de mi amigo. Le conté que mi amigo estaba acá, para que aceptara que yo probara suerte. [...] "Bueno, iquieres irte? Prepara tus papeles...", me dijo mi padre y eso hice. (Lautaro, 1974)

Los años '90 será el período considerado como el éxodo de los peruanos ${ }^{8}$, pues aumenta su migración a distintas partes del mundo. Argentina será uno de los lugares de mayor migración de peruanas (más que peruanos) de clases medias, medias-bajas (Bologna, Falcon Aybar, 2012; cf. Rosas, 2007). "La migración peruana [...] ha registrado un crecimiento importante a partir de la década del noventa, siendo un fenómeno urbano [y feminizado]. Uno de los factores centrales que explica esta forma de migrar ha sido la creencia de que el mercado del trabajo argentino es más propicio para la inserción femenina" (Magliano et alii, 2013, p. 3). Época caracterizada por una migración motivada, principalmente, por cuestiones laborales en el marco del auge o asentamiento

\footnotetext{
7 Para un análisis pormenorizado sobre la idea de provisionalidad de las migraciones remitirse a Sayad, 2010.

8 Expresión no solo usado en el campo académico (Altamirano Rua, 1992; Paerregaard, 2013), sino también referenciado por una de las entrevistadas, en 2014, Ma. Elena: "Los [años] '90 fueron la época del gran éxodo de peruanos. No sólo vinieron a parar a la Argentina, sino al mundo. A cualquier parte que vas encontrás un peruano. Eran épocas malas allá" (Ma. Elena, 1998).
} 
del neoliberalismo en la región sudamericana. La mayoría migra con expectativas de conseguir trabajo, mejorar sus condiciones socioeconómicas y volver con un mayor patrimonio a su lugar de origen o migrar hacia otros lugares. A su vez, Perú enfrenta la mayor violencia política del último siglo que provocó desplazamientos masivos (CVR, 2003) y se incrementaron las solicitudes de asilo y refugio (Cicogna, 2009; Cerutti, 2005). Por otra parte, las remesas comenzaron a tener un rol importante, no solo para el Estado, sino para las familias que tenían un miembro en el exterior (OIM et alii, 2008). La migración peruana hacia Argentina se caracteriza en este periodo por su feminización, entre las investigaciones más significativas se encuentran aquellas interpretaciones que analizan cómo el género condiciona, junto a otros fenómenos, ciertas motivaciones y estrategias migratorias y cómo éste posibilita cambios en las representaciones y prácticas de los y las migrantes peruanas (Rosas, 2010).

Ya a fines de los años '90 la violencia política en Perú había mermado, aunque las condiciones socioeconómicas no mejoraron para la gran mayoría de la población. Se identifica una migración peruana hacia Argentina con una mayor diversidad de motivaciones de salida: búsqueda de mejores condiciones de vida, laborales, por educación, reunificación o proyectos familiares. Ya no serán solo migrantes de una clase social, sino que todas las clases migran, no solo a Argentina, sino a distintas partes del mundo donde los peruanos tuviesen redes sociales. Alberto, uno de los entrevistados, expone el papel de las redes familiares en destino:

Entonces mi mamá, en el '98, influenciada por mi tía, accedió a venir, para probar suerte. Mi tía ya vivía en Córdoba, desde el '96. [...] Mi mamá se vino a vivir en el '98. Y, ahí, comienza una relación entre Argentina y mi vida, digamos en el '98. [...] Yo llegue acá en el 2009 a Río Negro. Mi madre ya se había regresado a Lima en el 2001. Yo siempre le digo a ella, que ella se volvió por la crisis del 2001 de acá [de Argentina]. (Alberto, 2009)

Esta periodización nos permite interpretar las experiencias de los sujetos y construir hitos sobre las políticas de control migratorio atravesadas por diversos procesos socio-históricos, ya que no será lo mismo ser rechazado en frontera en los años '70, donde los peruanos migraban principalmente por estudio, en el marco de "políticas de deportación por subversión" (Alvites Baiadera, 2017a), que a mediados de la década del 2000, donde priman las políticas de control de poblaciones enfocadas en la irregularidad/regularidad y donde los y las peruanas migraban generalmente por cuestiones laborales ${ }^{9}$.

\footnotetext{
9 En la tesis se analizaron las experiencias y dilemas de los sujetos antes de migrar, en el cruce de frontera y en las fronteras de permanencia en territorio argentino. Asimismo, se profundizó en las experiencias pasadas de los sujetos y un análisis sobre las políticas. Elementos que por cuestiones de espacio no serán desarrollados en este artículo.
} 


\section{Sobre experiencias y cruces de frontera}

Para interpretar las subjetividades la tensión entre sujeción y subjetivación (Chignola, Mezzadra, 2014), en el cruce de frontera, se recurre a la categoría sortear, la cual propone tener presente ese margen de maniobra, prácticas de revuelta, de sustracción, de fuga, de mimetismo o de negociación que pueden constituirse en las relaciones de poder y que, bajo ciertas circunstancias, pueden modificarse. Como aquella posibilidad de someter/se, consciente o inconscientemente, al arbitrio de la contingencia $y$, asimismo, evitar/ eludir y jugar frente a ciertas dificultades y situaciones, sortear obstáculos y dificultades que surgen en las distintas odiseas y dilemas "en las fronteras". En otras palabras, nos preguntamos cómo, en realidad, aceptan, rechazan, desobedecen, negocian y resignifican las políticas de control migratorio, sin asumir a priori que estos se sujetan a las condiciones que las políticas le fijan.

Si bien hay condicionantes políticos, sociales e históricos, y, en algunos casos, operan situaciones de dominación, las relaciones en las fronteras no están fijas ni definidas perpetuamente. Son espacios donde se establecen determinadas relaciones de poder, sujetos a diferentes momentos históricos, espacios de constantes encuentros, tensiones, conflictos y contestaciones, donde los sujetos sortean diversas dificultades, dilemas y movilizan estrategias y experiencias pasadas, donde los sujetos son, en parte, co-constitutivas, desigualmente, de éstas (Mezzadra, 2005; Mezzadra, Neilson, 2017). De este modo, cruzarlas no será lo mismo para todos los que desean hacerlo (Sassone, Cortes, 2010), ya que las fronteras se constituyen como zonas de retención y dispositivos de filtro (Balibar, 2005), marcadas tanto por prácticas de reforzamiento como por prácticas de atravesamiento (Mezzadra, Neilson, 2017), donde algunos sujetos son interpretados como "riesgos" para la seguridad de los Estados, mientras que otros son considerados "viajeros", sujetos "confiables" (Aquino, Varela, Décosse, 2013).

Así, los sujetos quedan supeditados al estrato político que ocupan en la jerarquía del sistema internacional el Estado del que son parte, lo que interviene en la capacidad de negociación de esa movilidad (Kalm, 2008). Y, a su vez, condicionados a los acuerdos que los Estados hayan realizado sobre el modo en que se puede ingresar, permanecer o no en un territorio. Estos cruces están sobredeterminados y los sujetos que allí transitan son interpelados de distintas maneras (Balibar, 2005).

Particularmente, en nuestro caso de estudio, en el cruce de frontera, los migrantes sortean la sospecha que pesa sobre ellos, sobre su condición de extranjero, un extranjero de cierto origen nacional que representa ciertas amenazas que se van modificando con el trascurso del tiempo. Los migrantes entrevistados recuperaron ciertos hitos de control que tuvieron que sortear, los 
cuales se concatenaron con diferentes momentos sociopolíticos. Es a partir del análisis de las experiencias que registraron los entrevistados que construimos estos hitos. Es decir, tales hitos podrían haber sido otros, o tendrían otra especificidad, si tomáramos como centro las políticas de control migratorio, sin embargo al poner foco sobre cómo los migrantes peruanos atraviesan, disputan y negocian las políticas de control migratorio se registraron y resaltaron estos y no otros controles en el cruce de frontera. Algunos de estos controles perduran en el tiempo, aunque con modificaciones; otros en cambio sobresalen más en un período que en otro ${ }^{10}$. La mayoría de los entrevistados cruzaron por vías terrestres y contaron con información sobre cómo transitar los controles gracias a las redes de amigos y familiares. A continuación desarrollaremos cada uno de los hitos reconocidos, los cuales son: sortear la sospecha por subversión, por falso turista, por ser portadores de enfermedades y por presentar documentación espuria.

\section{Sortear la sospecha por subversión}

Entre los años '50 y '80, Perú y Argentina fluctuaban entre gobiernos democráticos y dictatoriales; los cuales se caracterizaban por conservar políticas migratorias restrictivas y selectivas ${ }^{11}$. El movimiento de personas en frontera estaba sospechado por la circulación de posibles o supuestos "subversivos" o de cualquier sujeto que atentaré contra el orden y la seguridad nacional. Los entrevistados que migraron en esta época resaltan cómo eran los controles en este contexto:

¿Y, si se equivocaban? Yo no había hecho nada pero y sí... Ahí el miedo . (José, 1957)

Vine en el '75. El colectivo, que cambiamos como tres veces, lo pararon unas diez veces para controlarnos. Nos hacían bajar y nos apoyaban contra el colectivo. Nos revisaban y, después, todos arriba de nuevo. Eran tiempos duros. Nosotros veníamos a estudiar, no sabíamos nada de la Triple A [ $\left.{ }^{12}\right]$ El cruce de frontera fue espantoso. Casi como animales nos revisaron. En

${ }_{10}$ Para un análisis pormenorizado sobre la relación entre sospecha y migración véase Sayad, 2010.

11 La primera normativa migratoria en Argentina data de 1876 (Ley Avellaneda). Para este mismo período, Perú aprobaba la ley de inmigración de 1872-3, reformulada en 1893. En términos generales éstas promovían la inmigración europea y establecían mecanismos de selección. Estas normativas, con modificaciones, tuvieron vigencia hasta fines del siglo: Argentina derogaría su normativa en 1981 y Perú en 1992. Dichas leyes tuvieron como eje lo que podríamos signar, sintéticamente, como "seguridad nacional". La actual normativa argentina (2003) cambia el eje, apuntando a una nueva política migratoria nacional enfocada en los derechos. En 2015, Perú toma como modelos menos restrictivos de gestión migratoria las legislaciones de Uruguay, Ecuador y Argentina (Izaguirre, Busse, Vásquez, 2006). Estas dos últimas normativas, vigentes, no pueden comprenderse sin atender al proceso de regionalización de la política migratoria en Sudamérica (Cf. Domenech, 2010).

${ }^{12}$ La Alianza Anticomunista Argentina (AAA) fue un grupo parapolicial de la Argentina gestado a mediados de los años '70, por un sector del peronismo, la policía federal y las fuerzas armadas. 
un momento alguien dijo que buscaban a unos subversivos, aunque no sé si eso era cierto. (Jorge, 1975)

Si bien, los entrevistados se molestan por ciertas prácticas de los funcionarios estatales, "comprenden" estas prácticas como parte sine qua non del proceso de control, condición necesaria y de carácter obligatorio para que sea posible el ingreso a un territorio específico. De allí, que las representaciones que los migrantes tienen sobre sus prácticas en el cruce de frontera refiere a intentar pasar desapercibido y/o no estar asociado a acciones que pudieran considerarse "subversivas". La particularidad de este período es que la existencia legítima en el territorio, y por lo tanto del cruce de frontera, era posible siempre y cuando la presencia del sujeto migrante no estuviera asociada a la subversión. El rechazo en frontera, más que el no ingreso al territorio nacional, implicaba ampliar los riesgos de muerte: de detención, desaparición y asesinato.

Para no ser rechazados en frontera los sujetos tenían un trabajo previo, en Perú, que refiere a la búsqueda de la documentación que se les exigiría en frontera (este procedimiento se produce, con modificaciones, en todos los períodos). Este control a distancia se establecía principalmente desde la Embajada de Argentina: certificado de estudios secundarios finalizados, documento de identidad y antecedentes penales legalizados por la Embajada. Sin embargo, el tener toda la documentación no era garantía o condición necesaria para el ingreso al territorio, la condición de no subversión, era ineludible en este período. Aquí, las redes de amigos y familiares, aun incipiente en destino, sirvieron para realizar un "cruce más seguro", ya que éstas brindaron información sobre los controles y sobre las condiciones sociopolíticas imperantes.

\section{Sortear la sospecha por falso turista}

En Argentina, desde el año '85 se estableció formalmente un criterio para detectar aquellos sujetos que ingresaran en calidad de turistas a la Argentina, pero según la reglamentación establecida no lo fueran. Este rechazo se denominó falso turista, mecanismo para detectar la "presencia ilegítima" de extranjeros. Ésta tuvo modificaciones de forma en el año '95 y en 2014. Para sortear este rechazo los sujetos tienen que presentar pasaje de salida o retorno, demostrar dinero suficiente para vacacionar (denominado por los migrantes como bolsa de viaje) e indicar un lugar de residencia en destino (por ejemplo hotel donde se hospedará). La mayoría de los entrevistados, desde mediados de los años '80 hasta la actualidad, ingresaron a la Argentina en calidad de turistas, mostraron dichos requisitos a la Policía Auxiliar o al administrativo de la Dirección Nacional de Migraciones (DNM), como forma de indicar que el cruce era con fines turísticos. Una entrevistada cuenta cómo consiguió el dinero para su bolsa de viaje: 
Sí, para mi bolsa de viaje vendí el último toro de la familia. Vendí todo [...] Ya en frontera, presentamos nuestros papeles, los míos y los de mi marido. Todos [los que estábamos ahí, por ingresar a la Argentina] éramos turistas [risas]. Yo llegué y al otro día estaba trabajando cama adentro. Creo que conocí la plaza San Martín al mes [risas, plaza central de la ciudad]. (Raquel, 1998)

En este sentido, Raquel al sortear la figura de falso turista subvierte la función de dicho mecanismo, para posibilitar el cruce de frontera. A su vez, frente a este mecanismo de control estatal, y como forma de contrarrestarlo, surge la figura del pasador. Este es un individuo o pequeña empresa informal que, desde Perú, por un monto de dinero trae personas a distintas ciudades de Argentina. Estos pasadores no otorgan ningún tipo de garantía o seguridad a las personas que realizan el viaje, no les asegura llegar a destino, sino intentarlo. En el año '94 los Estados, peruano y argentino, acordaron identificar, investigar y detener, desde origen, a empresas o individuos que realicen este procedimiento. Sobre el rol del pasador las entrevistadas resaltan:

Cuando me comentaron que mucha gente se venía para acá, que se venían a trabajar y todo eso, entonces, lo analicé y dije "me voy". Agarré el negocio que tenía [comercio de venta minorista] y junte para mi pasaporte que en ese tiempo estaba a 60 o 70 dólares, más el pasaje y además había que pagar a un señor que nos traía para acá. Y le pagué los 150 dólares $[\ldots]$ nos trajo un señor. Como veinte chicas éramos, chicas, señoras que venían a trabajar. [...] A este señor lo llamé por teléfono. [...] El señor viaja para allá y buscaba gente. Los que querían venir se juntaban y entonces él decía "tal día voy". Entonces, cada uno iba juntando su plata. Otros quedaban con deuda con el señor, yo no. Se venían acá y después cuando juntaban le pagaban con trabajo. [...] El teléfono me lo dio una señora, la cual su hija viajó para acá conmigo. Nuestra primera parada fue en Chile, porque él organizaba cuales eran los pasajes y recorridos más cómodos para él, para ganar. Entonces, vinimos a Chile. En Chile entramos por Arica y después cruzamos la frontera y después llegamos a Salta (María, 1997). (Alvites Baiadera, 2017a, p. 181-182)

Había pasadores, así era mejor. Los contratabas desde allá. Te daban la bolsa de viaje y listo. (Manuela, 1995)

La conformación de redes sociales, principalmente de familiares y amigos, permite que el cruce de frontera a través de un intermediario (es decir pasadores), sea considerado más seguro que si lo hicieran solos. El uso de este mecanismo no es comprendido por las entrevistadas como un delito, sino como un mecanismo legítimo que habilita el ingreso al territorio argentino. Asimismo, el Estado con las restricciones impuestas a través de la figura del falso turista (entre otras medidas restrictivas) estimuló, en parte, la formación 
de una industria o comercio para el cruce de frontera ${ }^{13}$. Empresas privadas o pasadores que lucran y se benefician económicamente del control impuesto estatalmente.

\section{Sortear la sospecha de ser portadores de enfermedades}

En enero de 1991 se produce un brote de cólera en Perú, que se extenderá rápidamente por parte del territorio de América del Sur. En la Argentina, la epidemia de cólera fue considerada como una enfermedad importada (Abel, Caggiano, 2006) y llevó a que el Estado nacional desplegara, principalmente, a través de Gendarmería Nacional una serie de medidas para controlar las vías de entrada y de circulación, creando controles intermedios para reforzar la vigilancia de las fronteras (entre las provincias por ejemplo). Si bien los controles no se hacían exigiendo controles médicos de los sujetos, sí se generaron mecanismos de limpieza de los ambientes y controles sobre cualquier sujeto que presentara los síntomas visibles del cólera (vómitos y diarreas). En los controles en frontera el provenir del Perú, "lugar del brote del cólera", era visto como una amenaza a la salubridad pública. En las relaciones entre los funcionarios y los migrantes peruanos, el cólera se ponía en juego para la aceptación o el rechazo en frontera, lo cual por lo general promovía demoras en el cruce. Esto es expuesto en las entrevistadas que migraron en los años '90:

En los '90, cuando íbamos de visita a Perú, íbamos en Lan [empresa de aviones]. Antes de bajarnos nos rociaban con un spray de no sé qué cosa, y nos dijeron que era por el cólera. Me sentí un mosquito [risas]. (Elena, 1996) A mí no me paso nada. Pero a otros los hicieron bajar del colectivo. Mientras controlaban, escuché que decía los de Gendarmería "peruanos sucios". No me lo decían a mí, pero es feo eso. [...] ¿Por lo del cólera? La verdad que no sé, pero era el tiempo de eso. (Susana, 1994)

A mí me contó una amiga que llegó antes, cerca del '92 que escuchó en el colectivo que no nos querían acá por lo del cólera, como si tuviéramos la peste, dice que la trataron mal. Yo entre con pasador, normal. (Raquel, 1998)

Si bien, las entrevistadas no construyeron ninguna estrategia para sortear esta medida, buscaron distinguirse de aquellos sujetos que podrían considerase portadores del cólera: aquellos "peruanos sucios". Este mecanismo de control significó para las entrevistadas un lugar de incomodidad, al establecerse cierta cadena de equivalencia entre su nacionalidad (origen supuestamente del foco infeccioso) y la enfermedad. Es importante resaltar que, también, en Perú se planteó una campaña política que indicaba que la propagación del cólera era responsabilidad de un sujeto individual y producto de una enfermedad

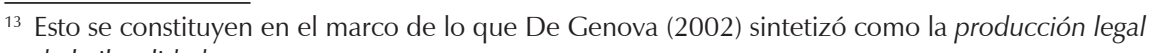
de la ilegalidad. 
importada. Una versión generalizada fue que el cólera se desencadenó en un barco asiático que visitó varios puertos peruanos cuyas deposiciones de tripulantes enfermos fueron arrojadas al mar, lo que actualizó viejos prejuicios sobre estos migrantes (Cueto, 2009). Estas representaciones se trasladaron en el cruce de frontera, al recordarles a las entrevistadas que sujetos individuales peruanos podrían ser los portadores de la enfermedad, donde ellas buscaron diferenciarse de estos.

\section{Sortear la sospecha por documentación espuria}

Aunque los requisitos de ingreso se han modificado con el paso del tiempo, todos los migrantes han transitado controles por su documentación. Siendo una de las condiciones de rechazo la presentación de documentos falsificados, incompletos o adulterados. Este mecanismo es una herramienta fundamental para permitir o no la presencia de un no-nacional en el territorio. Al llegar al cruce de frontera el migrante ya realizó otros controles en origen, en parte producto de la externalización de las fronteras de los Estado (Gil Araujo, 2011; Anguiano, López Sala, 2010; Casas-Cortes, Cobarrubias, Pickles, 2015). Con el fin de distinguir entre aquellos que pueden y no pueden entrar y salir, los Estados han desarrollado extensos sistemas de identificación, donde el pasaporte o el documento de identidad es un trámite ineludible que deben realizar. Como bien señala Torpey el pasaporte internacional contemporáneo es ante todo una expresión del intento de los Estados-nación modernos de afirmar su monopolio sobre los medios legales de movimiento. El pasaporte es un signo de distinción crucial que diferencia no solo entre ciudadanos y no ciudadanos en un territorio, sino también permite establecer la distinción entre nacionalidades (Torpey, 2000).

Los entrevistados, en Lima consultaron, además de sus redes particulares, a las autoridades locales y/o a la Embajada de destino sobre los requisitos necesarios para ingresar y permanecer en Argentina. En los últimos tiempos, producto de los acuerdos de residencia del Mercosur y Estados asociados y el acuerdo bilateral de residencia entre Argentina y Perú (2007), los peruanos con documento de identificación "interno" pueden ingresar a territorio argentino (es decir, sin la necesidad de pasaporte). Mientras que los entrevistados del primer período presentaron la documentación para ingresar como estudiantes, los de los siguientes dos períodos ingresaron, por lo general, en calidad de turistas e intentaron modificar su situación administrativa una vez establecidos en destino ${ }^{14}$.

\footnotetext{
${ }^{14}$ En otro artículo se desarrollan las fronteras de permanencia que los sujetos migrantes experimentaron: los procesos de irregularidad/regularidad, procesos de nacionalización, entre otros (cf. Alvites Baiadera, 2017b).
} 
En el último período, las redes sociales, por lo general familiares que Ilegaron en los años '90, otorgaron información y recursos para evaluar el cruce de frontera. Los migrantes de estos años cuentan con mayor información sobre los controles y sobre los requerimientos para no ser rechazados. La mayoría no tuvo inconvenientes en el cruce, aunque la preocupación, las dudas y los miedos de no responder a los requerimientos administrativos estuvieron latentes. Con la nueva modificación de la normativa argentina (ley 25.871), según los entrevistados, los controles se realizan más sobre los documentos que sobre los sujetos y el control es menos represivo y selectivo que con la Ley Videla (1981). Así, lo expresan las entrevistadas:

Me había traído el carnet de bombero por si acaso. Pensé, si me preguntan para qué viajo. (Doris, 2011)

Acá te preguntan a qué venís y a dónde vas, tipo pregunta de policía. No me trataron mal, pero te preguntan todo, cámara, huella digital. Ya estamos acostumbrados a esto, no es nada nuevo. Antes mi mamá, que vino antes, en los '90, me dijo que era peor. Estaba la ley vieja, la de la dictadura, ahora ya no. (Arturo, 2013)

Llegas y lo primero que te dicen: "ipapeles?" y uno presenta sus documentos. Creo que no me saludó, ni nada. (Lucía, 2000)

\section{Reflexiones finales}

Para analizar las políticas de control migratorio desde las experiencias de los sujetos migrantes, el artículo interpreta cómo los migrantes peruanos atraviesan, disputan y negocian en los cruces de fronteras su ingreso a territorio argentino. El artículo avanzó sobre diversas consideraciones teóricas y estableció una clave interpretativa de las entrevistas por medio de una periodización de la migración peruana en Argentina teniendo en cuenta las trayectorias de los sujetos y elementos sociodemográficos y condiciones sociopolíticas. A partir de esta periodización se establecieron diferentes hitos de control en el cruce de frontera, los cuales distinguimos analíticamente en: sortear la sospecha por subversión principalmente en los años 70, por falso turista desde mediados de los años 80, por ser (posibles) portadores de enfermedades, y sortear la sospecha por documentación espuria, primordialmente, desde los años 90 hasta la actualidad.

Un aspecto primordial del artículo es el supuesto teórico de que si bien los sujetos se encuentran atravesados por diversas relaciones sociales, imbricados y complejos mecanismos de poder específicos y prácticas estatales que estipulan quiénes son migrantes y quiénes no, estos no actúan mecánicamente. Nos preguntamos cómo en realidad aceptan, contestan o resignifican las políticas de control migratorio, sin asumir a priori que se sujetan a las condiciones que las políticas establecen. De este modo, a partir del análisis de las experiencias de 
los sujetos se observa, por un lado, que en algunos hitos sobresalen situaciones de dominación, es decir, sujetos que tiene casi nulo margen de maniobra o de resistencia. Por el otro, se encuentran situaciones donde las relaciones de poder permitieron -no sin conflictos, desigualdades e injusticias- el cruce de frontera.

Asimismo, si bien los entrevistaron contaron con información y datos brindados por las redes sociales de familiares y amigos para realizar su proceso migratorio $y$, a su vez, los controles son en parte similares en origen y en destino, la experiencia se realiza en primera persona y es el momento fundante que divide a un sujeto, ciudadano de otro territorio, en un no-nacional en el lugar de destino. En los cruces de frontera las normas que rigen ya no son las de origen, sino las de destino, normas que el migrante desconoce desde su experiencia. La duda se presenta como el primer dilema de frontera: el migrante se encuentra en un estado de incertidumbre. Por otra parte, si bien los entrevistados experimentan determinados mecanismos de control, en general, no se observan resistencias sobre cómo operan los Estados y las políticas de control migratorio. Los entrevistados se perciben más como sobrevivientes de esos controles. Los cuales consideran que, en términos generales, cualquier extranjero tiene que transitar. Como sobrevivientes, los migrantes peruanos sortean las políticas de control migratorio a través de simular la aceptación de las normas, es decir, alterar o emular la finalidad de las políticas y/o asimilaraceptar las prácticas de control estatal.

\section{Bibliografía}

ABEL, Lidia; CAGGIANO, Sergio. Enfermedades de Estado(s). Los inmigrantes y el acceso a la salud en una provincia de frontera. In: JELIN, Elizabeth; GRIMSON, Alejandro (eds.). Salud y Migración Regional. Ciudadanía, discriminación y comunicación intercultural. Buenos Aires: IDES, 2006, p. 57-90.

ALVITES BAIADERA, Angélica. Migraciones internacionales, fronteras y Estados. ¿Cómo interpretar el régimen de frontera desde América del Sur? Revista Desafíos, en prensa.

ALVITES BAIADERA, Angélica. Políticas migratorias y subjetividades migrantes: peruanos en Argentina. Tesis doctoral. Córdoba: CEA-FCS-UNC, 2017a.

ALVITES BAIADERA, Angélica. Control de ingreso y permanencia: miradas preliminares sobre las apuestas de "Cambiemos" en torno a la política migratoria argentina. In: PIÑERO, María Teresa; BONETTO, María Susana (comps.). Tensiones en la democracia argentina: rupturas y continuidades en torno al neoliberalismo. Córdoba: CEA-UNC, 2017b, p. 141-154.

ALTAMIRANO RUA, Teófilio. Éxodo: peruanos en el exterior. Lima: Fondo Editorial de la Pontificia Universidad Católica del Perú, 1992.

ANGUIANO, María Eugenia; LÓPEZ SALA, Ana María (eds.). Migración y frontera. Nuevos contornos para la movilidad internacional. Barcelona: CIDOB e Icaria editorial, 2010. 
AQUINO, Alejandra; VARELA, Amarela; DÉCOSSE, Frédéric (coords.). Desafiando fronteras. Control de la movilidad y experiencias migratorias en el contexto capitalista. México: Fronteras press, 2013.

BALIBAR, Étienne. Fronteras del mundo, fronteras de la política. Revista Alteridades, v. 15, n. 30, p. 87-96, julio-diciembre 2005.

BOLOGNA, Eduardo; FALCON AYBAR, María del Carmen. Tendencias de la migración peruana y boliviana en Córdoba. Un análisis a partir de datos censales. V Congreso de la Asociación Latinoamericana de Población. Montevideo, 2012.

CASAS-CORTES, Maribel; COBARRUBIAS, Sebastián; PICKLES, John. Changing Borders, Rethinking Sovereignty: Towards a Right to Migrate. REMHU, Revista Interdisciplinar da Mobilidade Humana, v. 23, n. 44, p. 47-60, enero-junio 2015.

CERRUTTI, Marcela. La migración peruana a la Ciudad de Buenos Aires: su evolución y características. Población de Buenos Aires, v. 2, n. 2, p. 7-28, 2005.

CHIGNOLA, Sandro; MEZZADRA Sandro. Fuera de la política pura: Laboratorios globales de la subjetividad. Revista Política Común, v. 6, 2014. Disponible en: < http://dx.doi.org/10.3998/pc.12322227.0006.005 > . Consultado: 12.01.2015.

CICOGNA, María Paula. Refugiados en Argentina. El rol de las organizaciones de derechos humanos de la comunidad peruana. Papeles del CEIC, v. 50, p. 1-34, septiembre 2009.

CONTRERAS, Carlos; CUETO, Marcos. Historia del Perú contemporáneo. Desde las luchas por la Independencia hasta el presente. Lima: Fondo editorial PUCPIEP-UP, 2013.

CUETO, Marcos. Entre la medicina, el comercio y la política: el cólera y el Congreso Sanitario Americano de Lima. In: CUETO, Marcos; LOSSIO, Jorge; PASCO, Carol (eds.). El rastro de la salud en el Perú. Lima: IEP, Universidad Peruana Cayetano Heredia, 2009, p. 111-150.

CVR. Hatun Willakuy. Lima: CVR, 2003.

DE GENOVA, Nicholas. Migrant 'Illegality' and Deportability in Everyday Life. Annual Review of Anthropology, v. 31, 2002.

DE GENOVA, Nicholas; MEZZADRA, Sandro; PICKLES, John (eds.). New Keywords: Migration and Borders. Cultural Studies, 2014. Disponible en: < http://dx.doi.org /10.1080/09502386.2014.891630>. Consultado: 12.02.2015.

DOMENECH, Eduardo. La gobernabilidad migratoria en la Argentina: hacia la instauración de políticas de control con 'rostro humano'. IV Congreso de la Red Internacional de Migración y Desarrollo "Crisis global y estrategias migratorias: hacia la redefinición de las políticas de movilidad". Quito, Ecuador: Facultad Latinoamericana de Ciencias Sociales (Sede Ecuador), mayo de 2010.

DOMENECH, Eduardo (comp.). Migración y política: un Estado interrogado. Procesos actuales en Argentina y Sudamérica. Córdoba: editorial de la UNC, 2009.

FALCÓN AYBAR, María del Carmen; BOLOGNA, Eduardo. Migrantes antiguos y recientes: Una perspectiva comparada de la migración peruana a Córdoba. Argentina. Migraciones Internacionales, v. 7, n. 1, El Colegio de la Frontera Norte, p. 235-266, enero-junio 2013. 
GIL ARAUJO, Sandra. Deslocalizar los muros de Europa. Los países de origen y tránsito de inmigrantes en el control migratorio de la Unión Europea. Revista Temas de Antropología y Migración, n. 2, p. 9-33, diciembre 2011.

GRIMSON, Alejandro. Fronteras, naciones y región. Fórum Social das Américas. Quito-Ecuador, 25 a 30 de julio, 2004.

IZAGUIRRE, Lorena; BUSSE, Erika; VÁSQUEZ, Tania. Discursos en tensión y oportunidades de cambio: la nueva Ley de Migraciones en Perú. In: RAMÍREZ, Jacques (coord.). Migración, Estado y Políticas. Cambios y continuidades en América del Sur. La Paz: Vicepresidencia del Estado Plurinacional de BoliviaCELAG, 2016.

KALM, Sara. Governing Global Migration. Suecia: Statsvetenskapliga institutionen, Lunds universitet, 2008.

LEÓN PRADO, Roxana. Construcción de la nacionalidad, políticas de Estado y peruanos en la ciudad de Córdoba (Tesis de maestría en Antropología). Facultad de Filosofía y Humanidades, Universidad Nacional de Córdoba, 2010.

LIBERONA CONCHA, Nanette. La frontera cedazo y el desierto como aliado. Prácticas institucionales racistas en el ingreso a Chile. Polis, Revista Latinoamericana, v. 42, 2015. Disponible en: < http://polis.revues.org/11308>. Consultado: 12.02.2016.

MAGLIANO, María José; PERISSINOTTI, María Victoria; ZENKLUSEN, Denise. Mujeres bolivianas y peruanas en la migración hacia Argentina: especificidades de las trayectorias laborales en el servicio doméstico remunerado en Córdoba. Anuario Americanista Europeo, v. 11, p. 71-91, 2013.

MEZZADRA, Sandro; NEILSON, Brett. La frontera como método. O la multiplicación del trabajo. Madrid: Traficantes de sueños, 2017.

MEZZADRA, Sandro. Multiplicação das fronteiras e práticas de mobilidade. REMHU, Revista Interdisciplinar da Mobilidade Humana, Brasília, v. 23, n. 44, p. 11-30, 2015.

MEZZADRA, Sandro. La cocina de Marx. El sujeto y su producción. Buenos Aires: Tinta de Limón, 2014.

MEZZADRA, Sandro. Derecho a fuga. Migraciones, ciudadanía y globalización. España: Traficantes de sueños, 2005.

OIM, INEI, DIGEMIN. Perú: características de los migrantes internacionales, hogares de origen y receptores de remesas. Perú: OIM, INEI, DIGEMIN, 2008. Disponible en: <http://www1.inei.gob.pe/biblioineipub/bancopub/Est/Lib0759/Libro. pdf>. Consultado: 01.09.2009.

PACECCA, María Inés; COURTIS, Corina. Inmigración contemporánea en Argentina: dinámicas y políticas. Serie población y desarrollo, CEPAL, n. 84, 2008.

PAERREGAARD, Karsten. Peruanos en el mundo. Una etnografía global de la migración. Lima: Fondo Editorial de la Pontificia Universidad Católica del Perú, 2013.

ROSAS, Carolina. Implicaciones mutuas entre el género y la migración. Mujeres y varones peruanos arribados a Buenos Aires entre 1990 y 2003. Buenos Aires: Eudeba, 2010. 
ROSAS, Carolina. ¿Migras tú, migro yo o migramos juntos? Los condicionantes de género en las decisiones migratorias de parejas peruanas destinadas en Buenos Aires. IX Jornadas Argentinas de Estudios de Población. Huerta Grande, Córdoba, 2007. Disponible en: <http://www.estadistica.chubut.gov.ar/biblioteca-virtual/ aepa/vision_migrar.pdf>. Consultado: 01.09.2009.

SASSONE, Susana María; CORTES, Geneviève. Cruzar y vivir la frontera entre Bolivia y la Argentina. Entre el Estado y el capital espacial del migrante. In: ANGUIANO, María Eugenia; LÓPEZ SALA, Ana María (eds.). Migración y frontera. Nuevos contornos para la movilidad internacional. Barcelona: CIDOB e Icaria editorial, 2010, p. 225-259.

SAUTU, Ruth; BONIOLO, Paula; DALLE, Pablo; ELBERT, Rodolfo. Manual de metodología. Construcción del marco teórico, formulación de los objetivos y elección de la metodología. Argentina: CLACSO, 2005.

SAYAD, Abdelmalek. La Doble ausencia. De las ilusiones del emigrado a los padecimientos del inmigrado. Barcelona: Antropos, 2010.

TAPIA LADINO, Marcela. Las fronteras, la movilidad y lo transfronterizo: Reflexiones para un debate. Revista Estudios Fronterizos, v. 18, n. 37, p. 61-80, septiembrediciembre 2017. Disponible en: <https://doi.org/10.21670/ref.2017.37.a04>. Consultado: 01.01.2018.

TEXIDÓ, Ezequiel; BAER, Gladys; PÉREZ VICHICH Nora; SANTESTEVAN Ana María; GOMES, Charles P. Migraciones laborales en Sudamérica: el MERCOSUR ampliado. Estudios sobre migraciones internacionales, n. 63. Ginebra: OIM Sector de la protección social programa de migraciones internacionales, oficina internacional del trabajo, 2008.

TORPEY John. The Invention of the Passport: Surveillance, Citizenship, and the State. Cambridge-UK: Cambridge, Univ. Press, 2000.

VERA DE FLACHS, María Cristina. Notas para la historia de la universidad en Argentina. Revista Rhela, v. 8, p. 65-112, 2006.

Recibido para publicación en 02.02.2018

Aceptado para publicación en 27.06.2018 Received for publication in February 02 ${ }^{\text {nd }}, 2018$

Accepted for publication in June $27^{\text {th }}, 2018$

ISSN impresso 1980-8585

ISSN eletrônico 2237-9843

http://dx.doi.org/10.1590/1980-85852503880005311 